\title{
KERK EN KERKVERBAND
}

\section{(Met besondere verwysing na Handelinge 15)}

\section{Inleiding}

Die vraag na die verhouding van kerk en kerkverband staan sentraal in die kontrovers tussen die verskillende denominasies. Die weg na die ware kerk kan in die doolhof van diskussies, soms erg skolasties en filosofies, alleen gevind word deur ook in die vraagstukke van die kerkreg noukeurig en gehoorsaam te luister na God se Woord.

Handelinge 15 tree in die kontroverse voortdurend tevoorskyn as locus classicus. ${ }^{1}$ Daarom sal Handelinge 15 vir ons as vaste staanplek dien om vanuit dié openbaring die vraagstuk te beoordeel.

Die verskil tussen Voetius en die Independente het veral oor die interpretasie van Handelinge 15 gegaan. ${ }^{2}$ Die Independente ontken dat die vergadering in Handelinge 15 die wesenskenmerke van 'n Sinode besit of dat dit die jus divinum positivum van die kerkverband en meerdere vergaderings openbaar. Hierdie nivellering van die betekenis van Hand. 15 bly steeds kenmerkend van die kerkregtelikes en teoloë wat Independentisties of independentisties-geneigd is. ${ }^{3}$

In onderskeiding van die Independente en hul geesgenote gaan ons saam met Calvyn, Voetius, Grosheide, Greydanus, Snyman e.a. Gereformeerde teoloë uit van die standpunt dat die verhouding tussen kerk en kerkverband, soos dit in Handelinge 15 geopenbaar word, dien as 'n normatiewe voorskrif, 'n normatiewe uitdrukking van God se wil, selfs sonder 'n nadere direkte gebod van God.

\section{Die kerk (ecclesia) in Hand. 15}

Hier is sprake van die ecclesia van Antiochië (14:27 en $15: 3$ ) en dié van Jerusalem $(15: 4,22)$. Ecclesia dui hier 'n plaaslike kerk aan. Wanneer daar sprake is van 'n streek word in vers 41 die meervoud, gemeentes in Sirië en Cilisië, gebruik. Hand. 15 is hierin homogeen met die res van die N.T. ${ }^{4}$ Ecclesia dui ook die universele kerk aan (Hand. 9 : 31; Ef. 1 : 22, 23; Kol. 1 : 18, 24). Universele kerk is dan die gelowiges soos hulle versprei is oor die hele aarde, en nie 'n denominasionele samevatting van 'n aantal gemeentes nie. Prof. Snyman het in sy uitnemende, reeds aangehaalde, rede aangetoon dat Paulus dit juis sorgvuldig vermy deur die heiden-christene saam te vat as ,al die kerke onder die heidene" (Rom. 16:4), en die Joodse Christene as ,al die kerke van Judéa wat in Christus is" (Gal. $1: 22$ ).

Uit die N.T. blyk dat die gelowiges in die ecclesia 'n werklike geestelike liggaam is. Daarom word dit genoem "wynstok en lote" (Joh. 15), 'n ,geestelike huis" wat uit "lewende stene" opgebou word in eenheid met "die lewende steen" Christus (1 Petr. 2 : 4, 5; ook Ef. 2 : 20-22). Die duidelikste word die kerk as 'n organiese 
eenheid geopenbaar in die briewe van Paulus waar hy die kerk "die liggaam van Christus" noem (Rom. $12: 4,5$; 1 Kor. $12: 12$ e.v.; Ef. 1 : 22, 23; Kol. $1: 18$ ).

Die eerste nadruk in "die liggaam van Christus" val op die eenheid van die kerk. Die eenheid bestaan in Christus (1 Kor. 12 : 12). Die kerk kom nie tot stand deurdat mense hulle deur onderlinge ooreenkoms verenig nadat hulle buite die kerk tot geloof gekom het nie. Die organiese eenheid van die kerk beteken dat die geheel voor die dele gaan. Die geloof is die inlywing in Christus en dus in die kerk as sy liggaam (Katg. sondag 7). Dit is die inkorporerende werk van die Heilige Gees. ${ }^{6}$ Die kerk is die uitverkore mensheid met wie Christus Hom deur sy vleeswording verenig as hulle Middelaar. En nadat Hy sy Middelaarswerk volbring het, woon Hy deur die Heilige Gees in die kerk as sy liggaam sodat die gelowiges „deur die Heilige Gees... ewig lewe en geregeer word" (Katg. antw. 76).

Hierdie kerk is nie slegs, onsigbaar vir mense, bekend by God „wat die harte ken" (Hand. $15: 8$ ) nie. Die onsigbare word sigbaar in die geloof en liefde van die gelowiges (Ef. 4:3,15). Die kerk is lewende mense wat in die eenheid van die geloof deur God saamgeroep is deur die Heilige Gees met die prediking van sy Woord, en geïnstitueer in die ampte.?

Die tweede nadruk in die kerk as liggaam van Christus lê in die verskeidenheid. Die kerk is nie 'n verstarde eendersheid nie. Dat die gelowiges saam een liggaam vorm beteken juis verskeidenheid in die eenheid, "want ook die liggaam is nie een lid nie maar baie" ( 1 Kor. $12: 14$ ). Die verskeidenheid in die eenheid is die wonderlike eiesoortigheid van die liggaam: die liggaam het nie 'n selfstandige bestaan buite die lede nie, en die lede bestaan nie buite die liggaam nie. Daarom kan die lede mekaar nie opsyskuif nie, maar in die kerk is elke lid noodsaaklik omdat God elkeen van die lede gestel het soos Hy gewil het.

Die ecclesia as liggaam van Christus is die algemene kerk. Die één uitsondering is 1 Kor. $12: 27$, waar die gemeente van Korinthe genoem word „liggaam van Christus" (sonder lidwoord). Alleen die kerk in universele $\sin$ is ,die liggaam van Christus", uitgedruk met die lidwoord by die predikaat. Dit beteken: die universele kerk tree in die plaaslike kerk tevoorskyn; dit is nie 'n stuk (kwantitatief) van die algemene kerk nie, maar 'n openbaring (kwantitatief) daarvan. ${ }^{8}$ Daarom word vir die plaaslike en die universele kerk dieselfde woord, ecclesia, gebruik. Omdat die plaaslike kerke een is, moet hulle met mekaar in kerkverband tree; die plaaslike kerke is wel selfstandig maar nie onafhanklik nie. ${ }^{9}$ Net soos die gelowiges verplig is om hulle in een gemeente te verenig, so is die gemeentes verplig om hulle in kerkverband met mekaar te verenig,9a omdat hulle in Christus één is.

Kerkverband is nie die universele kerk of 'n derde kerkbegrip nie. Dit is die sigbare openbaring van die universele eenheid van die kerke. Christus is nie Hoof van 'n aantal los van mekaar staande 
(independente) liggame nie, maar $\mathrm{Hy}$ is Hoof van die een liggaam, die één kerk, wat hier en daar plaaslik tot openbaring kom. Omdat die plaaslike kerke die universele kerk ter plaatse is, is Christus Hoof van elke plaaslike kerk.

\section{Die kerkverband in Handelinge 15}

Die twee kerke van Antiochië en Jerusalem gaan eenvoudig uit van, en handhaaf, hulle eenheid met mekaar. Hulle ag hulle nie los en onverbonde (independent) ten opsigte van mekaar nie. Toe daar in die kerk van Antiochië 'n verskil ontstaan en die partye mekaar in 'n debat nie kon vind nie, beslis Paulus nie alleen met apostoliese gesag nie. Die kerk in Antiochië handel die saak ook nie in outonome onafhanklikheid af nie. Terwyl die geskilpunt die wese van die kerk raak, soek Antiochië hierin eenheid met die universele kerk.

Daarom wend hulle hul na Jerusalem. Want te Jerusalem was die kring van die apostels. En in die apostels het Christus die Universele Kerk geïnstitueer. ${ }^{10}$ Daarom vorm die apostoliese woord vandag nog die eenheidsband tussen die kerke as die geïnspireerde belydenis van die kerk (Hand. 2 : 42; Ef. 2 : 19 e.v.). Die eenheid van die kerke op die universele fondament van die apostels kom tot uitdrukking in die Belydenis. Christus Self verg van die kerk belydenis teenoor die dwaalleer van „die mense" (Matt. $16: 5$ ). So stel Christus Self die eenheidsband van die kerk vas: Die kerk is belydeniskerk en word opgebou op die fondament van die belyde geopenbaarde waarheid (Matt. $16: 17$ ), sodat die kerk self pilaar en grondslag van die waarheid is ( 1 Tim. $3: 15$ ).

Antiochië gaan eenvoudig van die eenheid uit, en betrek nie net die apostels in Jerusalem nie, maar ook die kerk in Jerusalem. En in die eenheid van die kerk word die belydenisgrondslag van die kerke gehandhaaf teen die dwaalleer.

Antiochië gaan nie in Jerusalem op nie (Katolisisme); hulle vorm ook nie saam takke van 'n groter kerk (Kollegialisme)'11 nie. Die kerke vergader saam as gelykes, saamgebind deur die apostoliese getuienis as die grondslag van hulle gemeenskaplike geloofsbelydenis.

Die kerke het van die vroegste tye af ,een belydenis, een homologia in objectieve zin vast gelegd".12 En by die instituering van die Gereformeerde kerkverband na die Reformasie kon die kerke die konfessie ,als formulier voor kerkelijke eenheid erken, omdat zij uitdrukking van het gemeenschappelijk geloof was", ${ }^{13}$ terwyl die eerste sinode van die kerkverband te Emden (1571) dié simbool omhoog hef "tot ghetuyghnisse der onderlingher eendrachtigheid" 14 terwyl dit die kerkorde nog vasstel.

Die kerkverband word dus primêr gevorm deur die eenheid in belydenis. Die gemeenskaplike kerkorde is 'n toepassing van dié bestaande eenheid - of 'n afwyking (verbreking) van die eenheid - terwyl die meerdere vergaderings ' $n$ boefening van die kerkverband is. Die kerkverband bestaan of daar 'n kerkorde is of nie, of 
daar meerdere vergaderings sit of nie. Wanneer die meerdere vergaderings ontbind bestaan daar nie net plaaslike kerke langs mekaar nie, maar hulle bestaan in hulle onderlinge verbondenheid in die eenheid van hulle belydenis, d.i. hulle eenheid in Christus. Die kerkverband is nie atomisties die saamtrek van onafhanklike plaaslike kerke in een meerdere vergadering nie. Die kerkverband berus ook nie op die wil van die plaaslike kerke as 'n nuttigheidsmiddel wat die plaaslike kerke tot eie voordeel kan aanwend of nalaat omdat dit nie die wese maar slegs die welwese van die kerk betref nie. Kerkverband vloei uit die wese van die kerk voort. ${ }^{15}$ „De grondstructuren van de gemeente als lichaam van Christus vormen ook hier de duidelijke richtlijnen". ${ }^{16}$

Tussen Antiochië en Jerusalem is daar nie net 'n onsigbare geestelike eenheid in Christus nie. Die eenheid in Christus kom tot sigbare openbaring. Hulle is histories een (Hand. $11: 19-26$ ), op grond van die gemeenskaplike geloof in die Evangelie volgens die prediking van die apostels (Hand. $2: 42$ ). Die eenheid beoefen hulle in onderlinge liefde (Hand. $11: 29-30$ ) en in gemeenskaplike belydenis van die waarheid (Hand. 15). Die eenheid kom organisatories tot openbaring in die meerdere vergadering te Jerusalem.

\section{Die meerdere vergadering en die kerke in Hand. 15}

Die samestelling van die Jerusalemse vergadering

Die Jerusalemse vergadering is nie 'n apostelkonvent nie, maar 'n meerdere vergadering van kerke. Die kerk in Antiochië wend hom nie tot die apostels nie, maar ,pros tous apostolous kai presbuterous eis Jerousalêm". Die één lidwoord vat apostels en ouderlinge saam as één raad. Ook in vs. 6 en 22 is daar uitdruklik sprake van 'n vergadering van apostels en ouderlinge. By die vergadering moet die afgevaardigers van Antiochië bygereken word. Die apostel Paulus c.s. word as afgevaardigdes deur die raad ontvang en aanvaar in die vergadering, waaraan hulle deelneem (vs. 12), en waarvan hulle die besluit mede aanvaar (vs. 22). "Sun wijst wel aan, dat Paulus en Barnabas het eens waren met de genomen maatregelen", 17 terwyl die een lidwoord by Paulus en Barnabas hulle saamvat: Die afgevaardigdes van Antiochië.

Die vergadering is samegestel deur afvaardiging. Daarvoor gebruik v. 2 die woord tassó, wat beteken: om iemand tot iets te verorden of aan te stel. „Blijkens etaksan gaan allen, die gaan, als afgevaardigden". 18

Hierdie afvaardiging geskied deur die ekklesia. Hoewel daar nie 'n onderwerp by etaksan aangegee word nie, wys „van hulle" en „,hulle is deur die gemeente uitgelei" die gemeente aan as die een wat afvaardig. As afgevaardigdes verteenwoordig hulle die gemeente.

Die vergadering in Jerusalem is nie ' $n$ konvent nie. Dit is verteenwoordigers van kerke wat tot 'n gesamentlike besluit oor 'n vraagstuk (vs. 2) kom. „Bovendien mag worden gezegd dat Paulus en Barnabas de op de eerste reis gestichte kerken vertegenwoor- 
digen, ook al hebben die hen niet afgevaardigd. Maar ze waren als apostelen hun wettige vertegenwoordigers. Dan is al wat er aan kerken bestaat, te Jerusalem vertegenwoordigd". ${ }^{19}$

Die vergadering gee nie net advies aan Antiochië nie, maar „besluit" en lê 'n las op (vs. 28), nadat daar beraadslaging (veel debat - vs. 7) was en tot 'n gesamentlike beslissing geraak is (vs. $23-29$ ).

Die Jerusalemse vergadering is 'n sinode waarin ampsdraers as verteenwoordigers van kerke met mekaar na beraadslaging tot 'n bindende besluit geraak.

Hierdie vergadering van ampsdraers is nie losgemaak van en verselfstandig teenoor die gemeentes nie. Hulle verteenwoordig die gemeentes, so dat die gemeentes in hulle teenwoordig is. Die gemeente in Jerusalem deel in die ontvangs van Paulus c.s. In die midde van die gemeente doen hulle „verslag" (vs. 4). Dit lei tot 'n bespreking van die ,vraagstuk" (vs. 5). In die gemeenteverga. dering word nie oor die saak besluit nie. Maar wat vir ons belangrik is, is: die gemeentelede word nie as blote onmondige onderhoriges buite die bespreking gehou nie. In vers 22 word weer meegedeel dat ,die hele gemeente" saam met die sinode besluit het, waarskynlik by wyse van voorlegging en approbasie..$^{20}$ Dit bevestig die standpunt van Greijdanus dat ,de beraadslaging niet moet omgaan buiten de gemeente, maar voor haar front dient te geschieden, bepaald die betrekking heeft op de leer. Dan moet niet alles omgaan buite de gemeente zoodat eindelijk uit de verborgenheid eener beraadslagende vergadering een besluit op de gemeente word gelegd, waarvan zij tevoren niets wist, en terwijl zij van de gansche zaak en hare bespreking tevoren geheel onkundig was gehouden". ${ }^{21}$

Paulus laat hom afvaardig. Hy kon met apostoliese gesag die stryd besleg het in Antiochië, en selfs die dwaalleraars uitgeban het. Paulus self het geen twyfel i.v.m. die regte beslissing oor die vraagstuk gehad nie. Maar hy laat hom saam met ander afvaardig - dit is al ' $n$ beslissing met apostoliese gesag: die kerke moet self gesamentlik tot een belydenis kom. Dit word nog versterk deur Gal. 2 : 2: "maar ek het opgegaan op grond van 'n openbaring". Paulus handel dus nie in onderworpenheid aan die volksoewereiniteit van die gemeente nie ,but in the strength of devine commissioning and empowerment. Nor is it in conflict with this view that he also went on assignment from the church of Antioch. It is even possible that the revelation did not come to him personally".22

Die gesag van meerdere vergaderings berus nie primêr in die plaaslike kerke wat hulle godgegewe gesag saambring nie. Dit berus primêr in die gebod van God, die jus divinum positivum van die meerdere vergaderings; dit is nie afgeleide gesag nie, maar oorspronklik deur God gegee.

\section{Die taak van die Jerusalemse vergadering}

Die vraagstuk (vs. 2) het ontstaan uit 'n plaaslike situasie. Maar ten grondslag daaraan het gelê ' $n$ belydenis vraagstuk wat die ganse 
kerk raak. Dit gaan om „die gebruik volgens Moses” (vs. 1), en daarmee is die Woord van God aan die orde. So herken Jakobus dit ook (vs. 21). Die kerk van Antiochië word oor die vraagstuk van die besnydenis gekonfronteer met die Woord van God, terwyl die hele probleem van die onderhouding van die seremoniële wet gekonsentreer word in die besnydenis. Wie dit onderhou, onderhou die Wet en behoort tot die ou verbondsvolk. Intussen is die besnydenis vir die Grieke en die Romeine afstootlik.

Die „vraagstuk" is dus 'n saak van belydenis wat die eenheid van die kerk raak. Dit gaan om die eenheid in Christus. Want die eis om besnydenis lui: wie hom nie laat besny nie, kan nie gered word nie (vs. 1). Dit is 'n vraag oor kerkinrigting en kerkregering. Maar ten grondslag daaraan lê die belydenis van die kerk as die diepste grond van sy bestaan: is Christus die enigste en genoegsame Saligmaker, of is daarby nog iets nodig?

Die tug is ook in die gedrang: moet die heiden-christene gedwing word om hulle te laat besny, anders is hulle buite Christus en moet hulle soos 'n heiden en 'n tollenaar geag word? Leertug moet of op Paulus en Barnabas toegepas word of op die ,sekere persone". Paulus en Barnabas se verset (staseós) is in dié lig begryplik. Die wese van hulle prediking en kerkregering is op die spel.

Die plaaslike twissaak raak die belydenisgrondslag van die ganse kerk en dus die kerkregering in alle kerke. Daarom kan Paulus nie alleen, en die kerk van Antiochië nie independent, die saak afhandel nie. Die vraagstuk verg belydenisvorming teenoor dwaalleer, en daarop gebasseerde kerkregering, deur die kerke gesamentlik.

Al is die saak vir Paulus en Barnabas, en ook vir die grootste deel van die gemeente (vs. 31), duidelik, verg dit tog beraadslaging in die kerkverband, nie net ter wille van die eenheid nie, maar ook om die saak vir die ander party tot helderheid en beslissing te bring: hulle is in hulle plaaslike stryd ook in stryd met die apostoliese grondslag van al die kerke.

Die eenheid van die kerke word gesoek in die eenheid van die belydenis, waaruit die kerkregering, liturgie en tug moet voortvloei. Dit staan direk teenoor die Kerkorde van die Nederlandse Hervormde Kerk, waar die eenheid berus op die oopheid van die belydenis, sodat die Kerkorde die akkoord van kerklike gemeenskap word.

\section{Die werkwyse van die Jerusalemse vergadering}

Soos alreeds geblyk het in die hantering van die vraagstuk te Antiochië, is die kerklike werkwyse nie dwang of oorheersing met stemming nie, maar oorreding.

Nadat die sinode in sitting gegaan het (vs. 6) het hulle die saak bespreek. Dit spring in die oog: die apostels beslis nie met apostoliese gesag nie. Daar is geen nuwe openbaring nodig om oor die vraagstuk te beslis nie. Daar word beraadslaag met veel debat. Daar was vóor- en teenstanders van die besnydenis.

Die hele debat word nie weergegee nie, maar slegs die gemo- 
tiveerde voorstel van Petrus, en die gemotiveerde amendament van Jakobus, want hierop het die besluit (vs. 23-29) berus.

Petrus gee nie 'n apostoliese uitspraak op grond van besondere openbaring nie, maar sluit aan by wat bekend is (vs. 7) en doen daarvan eksegese (vs. 14). Na Petrus se uitleg ,swyg” die ver. gadering. Die beginsel staan vas volgens God se geopenbaarde wil, maar die besluit is nog nie duidelik nie. Petrus het dit nie met 'n apostoliese dekreet bepaal nie. Barnabas en Paulus bevestig die uitleg van Petrus: God het sy wil ook in hulle arbeid met tekens en wonders so geopenbaar. En nog swyg die vergadering. Die swye sê: ons weet wat die beginsel is, maar ons weet nog nie raad met die praktiese situasie, en die Woord van God deur Moses nie.

Dan spreek Jakobus. Ook hy bevestig die beginsel. God het uit die nasies (eks etnón) vir Hom 'n volk (laos) verkies (labein) (vs. 14). En hiermee stem die woorde van die profete ooreen" (vs. 15) sê Jakobus.

Petrus het die Nieu-Testamentiese openbaring van God uitgelê Jakobus lê die Ou-Testamentiese openbaring van God uit. Daar loop één openbarings-historiese lyn deur al God se werk en openbaring (vs. 17 en 18 - partic. praes. poión). Dit is God wat deurlopend hierdie dinge openbaar en doen, en so sy raad volbring.

In die motivering van die voorstel, en dus van die besluit, staan sentraal: God se openbaring. Dit gee sekerheid.

Tog volg daar 'n „maar" in vs. 20. Dit staan teenoor die ,nie bemoeilik" van vs. 19. Die sinode moet die beginsel toepas in die praktiese situasie van 'n plaaslike kerk. Die Jodechristene en die heidenchristene moet één wees in één gemeente. Daar moet nie gedurig oor en weer ergernis gegee word nie. Die prinsipiële beslissing alleen verwyder nie al die wrywingspunte nie. Daar is gewoontes van die heidenchristene wat die Jodechristene grief, en die eenheid in die gemeente skaad. Daarom die "maar" van vs. 20. Vir ons onderwerp is dit van belang: die „maar" word gemotiveer deur die eenheid van die gemeente: die broederliefde (vlg. 1 Kor. 8-10), sonder om die belydenisgrondslag af te water.

\section{Die gesag van die Jerusalemse vergadering}

Die vergadering besluit. Die besluit is vervat in die brief. Dit bevat nie net advies nie, maar uitspraak en voorskrif.

Die outeurs van die brief is nie, soos weergege in die Afrikaanse vertaling, ook die „broeders”, d.w.s. lidmate van Jerusalem nie. Broeders staan sonder lidwoord by apostels en ouderlinge. Ons vertaal dus: „die broeders apostels en ouderlinge”. Die gesagsuitoefening is wel broederlik, nie heersend, maar tog amptelik. Dit moet gehoorsaam word. Dit is 'n beslissing, dit lê 'n las op wat noodsaaklik is. Oor die dwaalleraars word 'n afkeurende oordeel gevel. Paulus en Barnabas word gehandhaaf. Die eenparigheid van die besluit beklemtoon die eenheid van die kerk in die belydenis teenoor die dwaalleer.

Die las wat die sinode oplê is noodsaaklik (vs. 28) maar nie 
altyd en oral geldende gebooie van God nie, want dit word nie as 'n altyd en oral geldende las opgelê nie (Rom. 14 en 1 Kor. 8). Die besluit gryp in bepaalde omstandighede binne bepaalde gemeentes in, want dit word geadresseer aan ,die broeders uit die heidene in Antiochië en Sirië en Cilicië". So bewaar die sinode sowel die eenheid in die waarheid as die eenheid in die liefde.

Ons moet ook let op die sterk uitspraak oor die onrusstokers (vs. 24). Hulle eis van "besny moet word en die wet moet onderhou" word in vs. 28 verwerp, en hulle eis word veroordeel as die van onrusstokers wat verwar. En nou laat die sinode dit nie by die uitspraak nie. Hy sien toe dat die orde en eenheid in die gemeente herstel word. Met eenparige besluit word daarvoor sorgvuldig uitgesoekte deputate na Antiochië gestuur. En hierdie deputate is nie apostels nie. Hulle tree dus met sinodale gesag en nie met apostoliese gesag op nie. So gryp die sinode direk in om die eenheid te herstel in die plaaslike kerk.

Die gesag van die sinode word in vs. 28 gemotiveer: „Want die Heilige Gees en ons het besluit". Die mees algemene verklaring hiervan lui: so mag dié sinode - en geen ander sinode nie spreek omdat die apostels daar teenwoordig was, terwyl hulle onfeilbaar gelei word deur die Heilige Gees.

Dit is natuurlik op sigself waar dat die apostels onfeilbaar deur die Heilige Gees gelei was. Die sinode besluit berus egter nie op hierdie onfeilbare apostoliese gesag nie. Dan was die vergadering, die diskussie, die uitleg van Petrus en Jakobus oorbodig en onnodig. Trouens, dan kon Paulus al die saak afgehandel het.

Die opgetekende motivering van die besluit bevestig nie hierdie eksegese van vs. 28 nie.

Hoe het die Heilige Gees ,besluit"? So soos Petrus en Jakobus ${ }^{23}$ dit uit die openbaring wat aan almal bekend is uitgelê het, deur die deurlopende openbaringslyn in Ou en Nuwe Testament. Hierdie openbaringslyn kulmineer in die gawe van die Heilige Gees aan die heidene net soos aan die Jode (vs. 8). Ook hier, soos in die hele boek Handelinge, is die Heilige Gees in die sentrum van die openbaring. En die gawe van die Gees aan die ,heidene” bring Petrus tot formulering van die belydenis, teenoor die dwaalleer in is. 1: "Maar ons glo dat ons deur die genade van die Here Jesus Christus gered word op dieselfde manier as hulle ook" (vs. 11).

D:e Heilige Gees spreek in die vergadering deur die Woord. En daarmee is, soos Calvyn dit uitdruk, Christus in die voorsitterstoel. So oefen $\mathrm{Hy}$ in die meerdere vergaderings sy Koningskap uit: Hy is die Koning wat die kerke regeer deur sy Woord en Gees. „Daarom wordt de Geest wel eens genoemd de regent en stadhouder van Christus op aarde. En daarom is er geen legitieme kerkregering buiten de Heilige Geest om. De Geest bindt zich hierbij echter aan Zijn eigen Woord, waarin $\mathrm{Hij}$ de wil van de Koning der kerk bekend maakt (Joh. 16:14). Alzo bezit het Woord van God regeerkracht". ${ }^{24}$

Met hierdie verklaring kry ,en ons” ook werklik sin. Dit is 
geen uitsondering van die apostels uit die vergadering nie (vgl. vs. 23 ), en dit verhef ook nie die vergadering met eie gesag naas die Heilige Gees nie. Maar die vergadering het besluit onder leiding en bestuur van die Heilige Gees ,wat hun door het Woord Gods voorgeschreven was". ${ }^{25}$ In hierdie sin mag elke sinode dieselfde uitspraak doen; trouens, geen sinode mag anders besluit nie.

Die gesag van 'n sinode is die gesag van die Woord. Dit is nie 'n ander soort gesag as die gesag van 'n kerkraad of van die prediking nie. Daar is nêrens in die kerk 'n ander gesag nie. Daar is net verskillende bedieninge op verskillende terreine van dieselfde Koninklike gesag van Christus wat die Heilige Gees in die Heilige Skrif vasgestel het. Die gesag van 'n meerdere vergadering berus primêr op die positiewe goddelike reg van die vergadering om die Woord van God uit te lê en te bely sodat dit per besluit aan die kerke opgelê kan word ter wille van hulle eenheid in Christus.

\section{Praktiese toepassing}

Uit die voorgaande het dit algaande duidelik geword dat die vasstelling van die verhouding tussen kerk en kerkverband in art. 29-36 van die Kerkorde van die Gereformeerde Kerk in S.A. nie maar berus op onderlinge ooreenkoms volgens eise van nuttigheid nie. Die artikels is toepassing van wat die Heilige Skrif voorskryf. Daarom moet die artikels nooit anders as in die lig van die Skriftuurlike beginsels wat daaraan ten grondslag lê, toegepas word in die Kerkregering nie. Dan alleen sal Christus die alléén-heerskappy voer in kerk en kerkverband.

\section{Slot}

Omdat dit samevattend is en berus op 'n studie van die hele Nuwe Testament sluit ons, ter vergelyking, af met die volgende aanhaling uit die uitnemende artikel ${ }^{26}$ van prof. Snyman:

„Oor die kerkverband kan dus gesê word: Dit vloei voort uit die wese van die kerk as die liggaam van Christus.

Dit is gegee in die optrede van die apostels, in die maatreëls wat hulle vir al die kerke getref het.

Dis ook gegee in die onderlinge hulpverlening, in die gemeenskaplike geloofsbelydenis en die handhawing daarvan.

Dit is ook in feite gegee in die kerkvergadering van Jerusalem (Hand. 15). Die besondere karakter van 'n kerklike vergadering tree daarin na vore as 'n vergadering waarin ook die Heilige Gees en die apostels teenwoordig is. Verder nog dat daarin beslissinge geneem word wat vir al die betrokke kerke bindend is (Hand. $15: 28$ ).

Oor hierdie vergadering in Jerusalem kan nog die volgende opgemerk word:

Dit gaan om die eenheid van die kerke (Gal. 2 : 9).

Dit het beslissingsreg.

Hierdie kerkvergadering is 'n onmiskenbare aanwysing vir die 
kerke tot gesamentlike opbouing van die liggaam van Christus op die grondslag van dic apostoliese woord onder leiding van die Heilige Gees (Ef. 4 : 12 e.v.)."

Kimberley.

J. J. van der Walt.

(Gelewer voor die G.T.V. Johannesburg, Oktober 1970)

1 Dr. M. Bouwman: Voetius over het gezag der Synoden; S. J. P. Bakker, Amsterdam, 1937, p. 135.

qui locus in controversia de synodis est fundamentalis.

2 Idem.

3 Vgl. J. van Dalen: De Schriftuurlijke beginselen van het kerkrecht; Oosterbaan en Le Cointre, Goes, 1946.

4 Vgl. W. J. Snyman: Die gebruik van die woord „Kerk" in die Nuwe Testament; Dic Westelike Stem, Potchefstroom, 1949.

5 Vgl. (a) B. B. Keet: Orde in die Kerk; N.G. Kerk-uitgewers, Kaapstad, 1963, p. 36. (b) J. A. S. Oberholster: Die Gereformeerde Kerke onder die kruis in Suid-Afrika; H.A.U.M., Kaapstad, 1956, p. 84 e.v. (c) Kerkorde der Nederlandse Hervormde Kerk; losbandige uitgawe, Boekencentrum, 's Gravenhage, 1959, art. 1

6 Dr. L. Floor: De Nieuwe Exodus; ongepubliseerde proefskrif, 1969, p. 269.

7 J. H. Roberts: Die opbou van die kerk volgens die Efese-brief; V.R.B., Groningen, 1963 , p. 122 e.v.

8 Dr. F. W. Grosheide: Kommentaar op het Nieuwe Testament; H. A. Bottenburg, Amsterdam, 1932, p. 425, voetnoot 1.

9 W. J. Snyman: Artikel in Die Kerkblad 27.7.66: „Oor Kerkverband".

9a W. J. Snyman: a.w., p. 14. M. Bouwman: a.w., p. 119/120.

10 W. J. Snyman: a.w., p. 10.

11 Th. L. Haitjima: Nederlandse Hervormde Kerkrecht; C. F. Callenbach, Nijkerk, 1951, p. 113 e.v.

12 A. D. R. Polman: Onze Nederlandse Geloofsbelijdenis, Deel I, Wever, Franeker, sj., p. 48.

13 H. Schokking: De Leertucht in de Gereformeerde Kerk van Nederland tusschen 1570 en 1620, Amsterdam, 1920, p. 184.

14 Fmden 1571, art. 2. By P. Biesterveld en H. H. Kuyper: Kerkelijk Handboekje; J. H. Bos, Kampen, 1905.

15 W. J. Snyman:Die Kerkblad, a.w.

16 H. Ridderbos: Paulus; Kok, Kampen, 1966, p. 536.

17 Dr. F. W. Grosheide: a.w., Die Handelingen der Apostelen I, p. 59.

18 Idem, p. 19.

19 Idem, p. 25.

20 Idem, p. 58.

21 S. Greijdanus: Schriftbeginselen van Kerkrecht inzake meerdere vergaderingen; Enschede, p. 36.

22 a) H. N. Ridderbos: The New International Commentary on the New 'Testament, The Epistle of Paul to the Churches of Galatia; Eerdmans, Grand Rapids, p. s0. b) IIenny Alford: Greeck Testament. Vol. III. 
Revingtons, Londen, 1871, p. 13.

23 Jakobus is die broer van die Here (Gal. $1: 19$ ) en nie 'n apostel nie, volgens Grosheide: a.w., kommentaar by Hand. 15 : 13. Ook H. N. Ridder. bos: a.w., Kommentaar by Gal, 1 : 19.

24 J. Hovius e.a.: Kerk en Woord; Ton Bolland, Amsterdam, 1969, p. 82.

25 Johannes Calvyn: De Handelingen der Apostelen; uit Latyn vertaal deur ds. G. Wielenga; Kok, Kampen, 1900, p. 137.

26 Die Kerkblad 27.7.66. 